\title{
Resenha
}

\section{Matriz Pentecostal Brasileira: Assembleias de Deus 1911-2011}

Gedeon Freire de Alencar

Editora Novos Diálogos

Rio de Janeiro, 2013. 383 p.

Um dos campos que mais vem sofrendo transformações nas últimas décadas na sociedade brasileira é o religioso. Certamente, sua principal força propulsora é a grande expansão do pentecostalismo entre a população brasileira. Importante lembrar que, segundo os dados do IBGE ${ }^{1}$ os evangélicos ascenderam de 6,6\% em 1980 para 22,2\% da população brasileira em 2010, que em números absolutos significa um salto de cerca de 7,8 milhões para mais de 42 milhões de pessoas. Ainda segundo o IBGE, os pentecostais respondem por cerca de $60 \%$ dos evangélicos no contexto do campo religioso brasileiro. Desta forma, é de fundamental importância a produção de trabalhos que tenham como objetivo compreender de perto tal fenômeno. Neste sentido, o trabalho de Alencar é um grande avanço, pois se trata do mais completo trabalho sobre a maior igreja evangélica brasileira - e segunda maior do país - a Assembleia de Deus (doravante AD).

Fruto de sua tese de doutorado no Programa de Pós-graduação em Ciências da Religião da PUC-SP, o trabalho que Alencar nos traz é produto de minuciosa pesquisa, seja nos arquivos do Centro de Estudos do Movimento Pentecostal, ligado à Casa Publicadora das Assembleias de Deus (CPAD), seja nas entrevistas com pastores e lideranças da $\mathrm{AD}$, ou ainda em arquivos conseguidos na Suécia, por intermédio da jornalista sueca Kajsa Norell, também pesquisadora da $\mathrm{AD}$ no Brasil. Alencar define a $\mathrm{AD}$ como uma "das sínteses mais próximas da realidade brasileira” (ALENCAR, 2013, p.17), compartilhando muitas contradições que são inerentes do próprio país e que a $\mathrm{AD}$ reproduz. Uma questão central para a compreensão de como a igreja se

\footnotetext{
${ }^{1}$ Censo do Instituto Brasileiro de Geografia e Estatística (IBGE) de 2010.
} 
estabelece e cresce no Brasil passa por sua trajetória de um pentecostalismo híbrido: fundada por suecos vindos dos EUA em Belém do Pará, no contexto do ciclo da borracha. Como foi criada a partir de uma dissidência batista e moldada para ser diferente da igreja luterana estatal sueca, a AD forma-se sem uma liderança única e centralizada. Como salienta Alencar, os missionários fundadores Gunnar Vingren e Daniel Berg, que hoje são reconhecidos como símbolos assembleianos da época, só tiveram sua imagem lapidada como tal posteriormente (OP. CIT, p. 29).

Desta forma, o autor propõe um modelo de compreensão, nomeado "Matriz Pentecostal Assembleiana Brasileira" (MPAB), no qual a $\mathrm{AD}$ não é entendida como única, mas plural (ADs), enquadrada no que Alencar nomeia assembleianismos. Tal como o Brasil, as ADs possuem, para além de elementos identitários comuns que se permita percebê-la enquanto uma igreja, uma formidável diversidade, acompanhando a lógica da própria pluralidade da sociedade brasileira. Os assembleianismos - urbano, rural, difuso e autônomo - são tipos ideais que dão auxílio na tarefa de compreender tal diversidade. Juntamente com essa tipologia é proposta uma análise sócio-histórica do fenômeno a partir de três categorizações periódicas: o movimento pentecostal (1911-1946), a instituição pentecostal (1946-1988) e a corporação pentecostal (1988-2011).

Ao longo da leitura do texto de Alencar, não é difícil identificar qual é sua principal referência teórico-metodológica: a sociologia compreensiva de Max Weber. Embora dialogue com outros autores clássicos da sociologia da religião, como Pierre Bourdieu e Daniele Hervieu-Leger, suas teses estão sempre em diálogo com o clássico sociólogo alemão. No capítulo 2, Teorização, História e Tipologia, é apresentada uma síntese das principais elaborações de Weber no campo do estudo sociológico da religião e também algumas questões de método. A análise sócio-histórica posterior de Alencar acerca das ADs é construída a partir da teoria weberiana dos tipos de dominação: tradicional, carismática e racional. Um mérito do autor aqui é utilizar-se bem desse instrumental teórico, dando sentido e inteligibilidade à complexa trajetória das ADs. Um bom exemplo disso é a construção idealtípica dos assembleianismos. O assembleianismo rural é um tipo dominante nas primeiras décadas de existência das ADs e até hoje ainda se faz muito presente no ethos assembleiano. Alencar o elabora com quatro características fundamentais: a mentalidade rural, a estrutura patriarcal e estamental da liderança, o abismo comportamental entre Sedes e Congregações e a densidade assembleiana nas pequenas igrejas e cidades. Já o assembleianismo 
urbano é marcado pela sua diversidade e multiplicidade, não assumindo automaticamente valores típicos dos centros urbanos. A ênfase no controle moral, tão importante e marcante no assembleianismo rural, é no contexto urbano mais deficiente. Por sua vez, o assembleianismo autônomo seria intrínseco ao próprio modelo pelo qual as ADs foram estabelecidas no Brasil, onde a ligação entre as igrejas é espiritual e não institucional. Sua prática eclesial é de muita heterogeneidade e seu pertencimento ao assembleianismo dá-se mais na manutenção de características típicas, como hinologia, estilo de lideranças e usos e costumes. O último tipo ideal de assembleianismo é o difuso, cujo pertencimento às $\mathrm{ADs}$ dá-se mais nas expressões básicas dos crentes (“- Paz do senhor, irmão!”), hinários entre outras. Controle de moralidades e características teológicas aqui são relativizadas, de acordo com o contexto.

No capítulo 3, O Movimento Pentecostal: a iluminação do carisma - 1911-1948, Alencar analisa o desenvolvimento e o crescimento das ADs em um país ainda rural, mas em vias de urbanização, com grandes fluxos imigratórios - o que vai ser fundamental para a expansão da igreja. Nesse período não há sequer uma figura jurídica que responda ou represente as ADs. A ênfase aqui é na caracterização do fenômeno como um movimento pentecostal. A partir do instrumental weberiano dos tipos de dominação, o autor salienta o papel do carisma como fundamental para se compreender a igreja, na medida em que, nesse contexto inicial, não há distinção entre clero e membros, e a "promessa" é para todos. Nesse momento, as ADs se caracterizam por serem formadas por pequenos templos (templos casa), darem pouca importância para a educação teológica e desenvolverem uma teologia voltada para o sofrimento, de grande negação do mundo. Um dos destaques do capítulo é o resgate que Alencar faz de Frida Vingren, esposa do missionário fundador Gunnar Vingren, que exercia importantes papéis em sua congregação e escrevia o mais importante veículo de comunicação da igreja, o jornal Mensageiro da Paz (que é relevante até os dias atuais). Derrotada nas lutas internas da AD de seu tempo, fortemente machista, "a figura de Frida na história oficial é apagada, quase inexistente” (IDEM, p. 116). Tais lutas internas são muitas e são personificadas na disputa de Vingren e Samuel Nystron (também sueco) pelo direcionamento que a igreja viria a ter, no qual o segundo é o vitorioso. O movimento está em vias de institucionalização.

Em outubro de 1946 é realizada a primeira Convenção da igreja em Recife, onde há um estabelecimento de uma personalidade jurídica. Desta forma é 
fundada a Convenção Geral das Assembleias de Deus no Brasil ${ }^{2}$. Trata-se do segundo período - 1946 a 1988 -A Instituição Pentecostal: o avanço da tradição, discutido no quarto capítulo do livro. Aqui a palavra-chave seria a tradição, simbolizada pelo longo pastorado dos principais líderes assembleianos do período. Uma tradição inventada a partir da construção mítica das primeiras lideranças suecas, que vai ser respeitada e ressignificada pelas lideranças brasileiras que se impõem no período. Ainda aqui há uma rejeição à educação teológica formal, que começa a ser rediscutida e torna-se objeto de tensões. Sua base é a disciplina, perante os "perigos do mundo" e a fragmentação do pentecostalismo brasileiro, que vive nesse período sua segunda "onda" de expansão (FRESTON, 1994). Sua disputa interna mais destacada é a entre a "Missão", sob a liderança de Cícero Canuto; e "Madureira", pastoreada por Paulo Macalão. Sob a disputa simbólica da tradição, Alencar salienta que a disputa entre os dois é sobre quem é mais conservador (ALENCAR, 2013, p. 211). Neste sentido, as disputas entre os ministérios ajudam a fragmentar as ADs, ao mesmo tempo em que as lideranças paroquiais se fortalecem. Tudo em nome da tradição, que, como nos ensina Weber, é um grande e eficaz instrumento de dominação.

Em 1988, com a expulsão do Ministério de Madureira da CGADB, iniciase o terceiro período problematizado por Alencar: 1988 a 2011 - A Corporação Pentecostal: a (ir) racionalidade dos poderes, quinto capítulo do livro. Aqui, a narrativa que desde o começo possui um tom crítico assume também uma perspectiva ácida, crê-se devido ao recrudescimento das disputas internas e do próprio formato corporativo que a igreja assume. As ADs, cuja força e fraqueza vêm de sua estrutura "grande, mas fracionada; organizada, mas desarticulada; presente, mas invisível” (IDEM, p. 218), encontram-se em disputa em torno dos seus próprios assembleianismos e tendo que conviver e se adaptar ao crescimento das igrejas neopentecostais, notadamente a Igreja Universal do Reino de Deus (IURD), que se expande no mesmo território socioespacial das ADs. Nesse contexto, a elite dirigente da igreja prospera, adquirindo formas de corporação, com interesses políticos e econômicos cada vez mais crescentes. Entre as muitas disputas das lideranças, a que mais ganha destaque, inclusive nas comemorações do centenário das ADs, é a entre

\footnotetext{
${ }^{2}$ Segundo dados da própria, a mesma foi fundada em 1930 e registrada em 1946. Cf. http:// www.cgadb.com.br/. Acesso em 29 de maio de 2014.
} 
José Wellington Bezerra da Costa, presidente da CGADB, e Samuel Câmara, pastor presidente da $\mathrm{AD}$ mãe de Belém do Pará. O padrão administrativo agora passa por uma "racionalidade administrativa eclesiástica" (IDEM, p. 268), mas que assume como política interna um formato "patrimonialista familista” (IDEM, p. 269). Paralelamente à disputa entre Bezerra da Costa e Câmara, cresce a figura do pastor que, símbolo do assembleianismo autônomo, vai se tornar o pastor assembleiano mais conhecido do Brasil: Samuel Malafaia, que faz de sua AD (Vitória em Cristo) o maior exemplo de corporação pentecostal no seio das Assembleias de Deus. "A teologia em si é o que menos importa no discurso de Malafaia e seu grupo. Importante mesmo é o lucro que isso dá e o resultado político no presente e futuro" (IDEM, p.281).

Passada a limpo a trajetória das ADs, temos em perspectiva que a igreja mudou tanto quanto o Brasil, acompanhando seu crescimento dentro de suas contradições. As ênfases teológicas iniciais baseadas no sofrimento e renúncia não se perdem totalmente, mas são matizadas, enquanto as estruturas eclesiais tornam-se mais profissionais, seguindo o processo de racionalização inerente à modernidade. As mulheres, com exceção de alguns ministérios autônomos, continuam alijadas das funções principais da igreja, embora tenham um importante papel na dinâmica interna de funcionamento da igreja, pois são a maior e mais dedicada parte de sua membresia. Sem a aprovação delas, dificilmente um cantor ou liderança ganha destaque. Seria uma espécie de empoderamento das bases assembleianas?

Por fim, Alencar indaga: "Há vida depois do centenário?", elaborando o capítulo final do livro, no qual são analisadas principalmente os meios e as consequências do processo de crescimento que as ADs experimentaram nos últimos anos. $\mathrm{O}$ autor salienta que a identidade assembleiana mudou muito nestes cem anos, acompanhados pelos seus elementos centrais, a saber: os Ministérios, a Educação Teológica, as Relações de gênero, a Mídia, as Convenções e os Templos. Cada um desses mudou, mas continuam como pilares dessa identidade.

Como palavras finais, temos no livro de Alencar uma primordial análise para compreensão do fenômeno das ADs e do próprio pentecostalismo brasileiro. Torna-se impossível ignorar as contribuições que a obra nos traz, acompanhada por um eficiente corpo teórico e um olhar próprio de Alencar, que é ao mesmo tempo próximo e crítico; apaixonado e ácido; rigoroso e irônico. Em 1994, Freston afirmava: "Está na hora de a sociologia da religião lançar-se ao estudo das grandes igrejas pentecostais enquanto instituições em 
evolução dinâmica" (FRESTON, 1994, p. 68). Com o trabalho de Alencar essa hora parece que chegou, mesmo que com quase vinte anos de defasagem. Sem dúvida, uma grande contribuição para a sociologia da religião.

Alexander Soares Magalhães*

\section{Referências}

ALENCAR, Gedeon Freire de.

(2013)MatrizPentecostalBrasileira:Assembleias de Deus 1911-2011. Rio de Janeiro: Novos Diálogos.

FRESTON, Paul.

(1994). "Breve história do pentecostalismo brasileiro.. . In: Alberto Antoniazzi; José BittencourtFilho; RubemCésarFernandes; Paul Freston; Wilson Gomes; Cecília Mariz; Pierre Sanchis; Ingrid Sarti; Rogério Valle (Orgs.); Nem anjos nem demônios: interpretações sociológicas do pentecostalismo. Petrópolis: vozes. p. 68.

\section{Recebido em}

maio de 2014

\section{Aprovado em}

junho de 2014

* Doutorando em Ciências Sociais pela Universidade do Estado de Janeiro (UERJ) e professor de ensino básico, técnico e tecnológico do Centro Federal de Educação Tecnológica Celso Suckow da Fonseca (CEFET - RJ). E-mail: alexird@yahoo.com.br. 